\title{
BMJ Open Ability to join the workforce and work productivity among drug users under methadone maintenance treatment in a mountainous area of Northern Vietnam: a cross-sectional study
}

\author{
Vuong Minh Nong, ${ }^{1}$ Victoria L Boggiano, ${ }^{2}$ Lan Huong Thi Nguyen, ${ }^{1,3}$ \\ Cuong Tat Nguyen, ${ }^{1}$ Long Hoang Nguyen, ${ }^{3}$ Tran Xuan Bach, ${ }^{4,5}$ Hung Van Nguyen, ${ }^{6}$ \\ Canh Dinh Hoang, ${ }^{6}$ Carl A Latkin, ${ }^{5}$ Minh Thuc Thi Vu ${ }^{7}$
}

To cite: Nong VM, Boggiano VL, Nguyen LHT, et al. Ability to join the workforce and work productivity among drug users under methadone maintenance treatment in a mountainous area of Northern Vietnam: a crosssectional study. BMJ Open 2017;7:e016153. doi:10.1136/ bmjopen-2017-016153

- Prepublication history for this paper is available online. To view these files please visit the journal online (http://dx.doi. org/10.1136/bmjopen-2017016153).

VMN and VLB contributed equally.

Received 27 January 2017 Revised 9 June 2017 Accepted 13 June 2017

CrossMark

For numbered affiliations see end of article.

Correspondence to Miss Lan Huong Thi Nguyen; nguyentlanhuong5@duytan. edu.vn

\section{ABSTRACT}

Objectives A major measure of treatment success for drug users undergoing rehabilitation is the ability to enter the workforce and generate income. This study examines the absenteeism and productivity among people who inject drugs (PWID) enrolled in methadone maintenance treatment (MMT) in Northern Vietnam. Setting We conducted a cross-sectional study in two clinics in Tuyen Quang province.

Participants A total of 241 patients enrolled in MMT. Primary and secondary outcome measures Patients' work productivity was measured using the WPAI-GH instrument (Work Productivity and Activity Impairment Questionnaire: General Health V2.0). We also collected additional characteristics about participants employment history, such as proficient jobs, whether they actively found a new job and be accepted by employers.

Results Most of the participants (>90\%) were employed at the time of the study. Rates of absenteeism (missed work), presenteeism (impairment while working) and overall loss of productivity were $15.8 \%, 5.6 \%$ and $11.2 \%$, respectively, as measured by the WPAI-GH questionnaire. The most proficient job was 'freelancer' (17.5\%), followed by 'blue-collar worker' $(10.6 \%)$ and 'farmer' (10.2\%). Only $26.8 \%$ of patients reported that they actively sought jobs in the past. About half of them had been refused by employers because of their drug use history and/or HIV status. We found no statistically significant difference between patients enrolled in MMT for $<1$ year and those who had been enrolled $>1$ year. Factors associated with higher work productivity included not endorsing problems in mobility, self-care or pain; being HIV-negative and having greater MMT treatment adherence.

Conclusion Our study highlights the high employment rate and work productivity among PWID in MMT programmes in remote areas of Northern Vietnam. The results can help to improve the quality and structure of MMT programmes across Vietnam and in other countries.
Strengths and limitations of this study

A cross-sectional study design was used without a comparison group.

- A small sample size may have reduced the statistical power of this study.

- Data are based on patients' self-reports, which may lead to recall bias.

\section{INTRODUCTION}

Injection drug use represents a major public health burden. Globally, there are more than 16 million people who inject drugs (PWID). ${ }^{1}$ It is widely documented that injecting drugs is associated with a high risk of acquiring HIV and hepatitis, as well as the risk of to drug overdose and mental health problems. ${ }^{23}$ These risk factors contribute to the higher mortality rate and lower quality of life among PWID compared with the general population. ${ }^{14}$ Yet the consequences of illicit drug use are not only health related. In both high-income and middle-income countries, using drugs has significant social and economic effects. The total economic cost of drug abuse in the USA from 2007 data was estimated to be more than US $\$ 193$ billion, with the major component was productivity losses. ${ }^{5}$ Similar results have also been found among Taiwanese PWID. ${ }^{6}$ The loss of work productivity among opioid-dependent drug users is an inevitable outcome of their reduction in health status, early mortality and difficulty finding legal means of employment. ${ }^{78}$

Methadone maintenance treatment (MMT) is known to be one of the most efficacious therapies for opiate addiction. ${ }^{910}$ PWID enrolled in MMT programmes 
can significantly reduce heroin and other opiate use. ${ }^{9}$ In addition, PWID enrolled in MMT are less likely to engage in criminal activities or be at risk of HIV acquisition; and more likely to improve their quality of life and socioeconomic status. ${ }^{911-16}$ Corsi et al found an increase in employment and self-derived income between baseline and 6 months after enrolment in an MMT clinic among 160 PWID in the USA. ${ }^{17}$ In Taiwan, Hsiao et al found that the mean length of unemployment was cut in half among patients enrolled in MMT, in conjunction with an increase in patients' monthly income. ${ }^{18}$

In Vietnam, the HIV epidemic is driven primarily by injection drug use. Approximately $10.3 \%-43.5 \%$ of the PWID in Vietnam are HIV-positive. ${ }^{19}$ Over the past 5 years, the HIV epidemic in Vietnam has seen remarkable growth in mountainous and remote areas of the country. For example, in Dien Bien and Son La, two provinces in the northwestern part of Vietnam, the HIV rate among PWID is estimated to be $30.9 \%$ and $25.9 \%$, respectively. ${ }^{19}$ To address this rise in HIV among PWID, there has been a rapid expansion of MMT in many provinces. In the year 2016, there were more than 200 MMT clinics present in 57 provinces and cities across Vietnam, providing treatment to about 46000 patients. ${ }^{20}$ Recent studies in Vietnam have highlighted the effectiveness of MMT in reducing HIV-related risk behaviours and health expenditure among PWID, as well as increasing their health status and quality of life. ${ }^{21-24}$ However, limited data exist about the socioeconomic impact of MMT. A study by Hoang et al indicated that MMT patients in an urban city in Vietnam saw improved employment rates and increased income, but their results did not measure actual productivity gained or lost by being enrolled in MMT. ${ }^{24}$ HIV prevention and treatment programmes in Vietnam are at risk of rapidly losing funding from international donors, and copayment services might be a potential way to cope with this problem. ${ }^{25}$ Yet in order to expand the programmes, their ability to join the workforce must be better understood. In this study, we assessed productivity and preferences about employment among PWID enrolled in two MMT clinics in a mountainous part of Northern Vietnam.

\section{METHODS}

\section{Study design and setting}

A facility-based cross-sectional study was carried out in Tuyen Quang, a mountainous province in Northeastern Vietnam from May to August 2015. It is estimated about 1100 PWID in the province, and MMT service has been provided for 388 patients. There were three MMT clinics in this province namely Tuyen Quang, Son Duong and Yen Son. Because Yen Son clinic only had nine patients, we involved two other MMT clinics with 277 patients currently receiving MMT. The Tuyen Quang clinic is in an urban area while the Son Duong clinic is located in a remote area of the province.

A convenience sampling technique was used to recruit the patients. Patients were invited if they were aged 18 years or above, available during the study period, able to answer a questionnaire in $20-25 \mathrm{~min}$ and willing to participate in the study. After introducing to the study, the patients were asked to give their written informed consent if they agreed to be study subjects. A total of 241 patients enrolled in the study, which accounted for $87.0 \%$ of the overall number of MMT patients in two clinics. Because there were only five female patients enrolling in the MMT programme in this province, we did not recruit them to the study. Therefore, all respondents were male.

\section{Measurements and instruments}

We conducted face-to-face interviews with the patients by using a structured questionnaire. The data collection team included master students in Public Health from Hanoi Medical University. The variables of interest are described below.

\section{Socioeconomic characteristics}

Participants' socioeconomic characteristics were recorded including education level (less than high school; high school; more than high school), marital status (single; live with spouse/partner; widow/separate/divorced) and employment status (unemployed, farmer/worker, self-employed, others) We calculated patients' age based on their year of birth. We also asked patients to report their monthly household income and then categorised into five quintiles (from poorest to richest).

\section{Work productivity}

Participants' overall productivity and loss of productivity due to their drug addiction were measured using the Work Productivity and Activity Impairment Questionnaire: General Health V.2.0 (WPAI-GH).$^{26}$ The instrument contains six questions that measures work lost due to an impairment in the last 7 days: Q1. Current employment; Q2. Hours missed due to a specified problem; Q3. Hours missed for other reasons; Q4. Total hours worked; Q5. The degree that problem affects productivity while working ( $0-10$ points scale, where 0 is the lowest degree) and Q6. The degree that problem impacts regular activities $(0-10$ points scale, where 0 is the lowest degree). We calculated four primary outcomes based on these questions, ${ }^{26}{ }^{27}$ including:

1. Per cent of work time missed due to health conditions (absenteeism): Q2/(Q2+Q4).

2. Per cent impairment while working due to health conditions (presenteeism): Q5/10.

3. Per cent overall work impairment due to health: Q2/ $(\mathrm{Q} 2+\mathrm{Q} 4)+[(1-\mathrm{Q} 2 /(\mathrm{Q} 2+\mathrm{Q} 4)) \times(\mathrm{Q} 5 / 10)]$.

4. Per cent impairment in activities due to health: Q6/10.

Moreover, we also collected additional characteristics about participants' employment history, such as the types of jobs they were proficient at, whether they actively sought jobs in the past and whether employers had offered them jobs or not (including reasons for being turned away if applicable). 


\section{Health status}

EuroQol-five dimensions-five levels (EQ-5D-5L) instrument was used to measure health-related quality of life (HRQOL) in five domains: mobility, self-care, usual activities, pain/discomfort and anxiety/depression. There are five levels of response for each domain: no problems, slight problems, moderate problems, severe problems and extreme problems. ${ }^{22} 28$ We also employed a visual analogue scale (VAS) to measure self-evaluated HRQOL. This scale had the score ranging from 0 ("The worst health state that you can imagine") to 100 ("The best health state that you can imagine").

We also asked patients to report their HIV status, history of suffering acute diseases in the last 4 weeks and experiencing chronic diseases in the last 3 months. Additionally, self-reported weight and height were collected to compute the body mass index, which can classify the patients into three groups 'underweight,' 'normal' and 'overweight/obesity'. Data about whether the patients received antiretroviral therapy (ART) was collected.

\section{Substances abuse characteristics}

Alcohol abuse was screened by using the Alcohol Use Disorders Identification Test-Consumption (AUDIT-C), an instrument having three items with the total score from 0 to $12 .{ }^{29}$ The higher score, the higher risk of alcohol abuse. If male respondents had a score $\geq 4$, they were categorised as hazardous drinkers. ${ }^{29}$ Respondents were categorised as current smokers, if they have ever smoked at least 100 cigarettes in their entire life and had smoked in the last 30 days. We also collected information about participants' concurrent drug use and the number of times they underwent drug rehabilitation and duration of methadone treatment. Concurrent drug use was defined as continuing use of illicit drugs during MMT in the past 30 days.

\section{MMT adherence}

Patients reported their adherence to MMT over the past 30 days on a 100-point VAS, where 0 indicated complete non-adherence and 100 indicated perfect adherence. The optimal threshold to identify 'adherence' was 95 point or above. ${ }^{30}$ The VAS has been proven to be an inexpensive and valid method for measuring medication adherence. ${ }^{31}$

\section{Statistical analysis}

In our study, we considered patients in treatment $\leq 12$ months as 'short-term' and $>12$ months as 'long-term'. Our hypothesis is that patients who undergo long-term treatment may have better outcomes than those who undergo short-term treatment. Then all results will be presented in the above subgroups. Mann-Whitney and $\mathrm{X}^{2}$ tests were used to detect statistical differences among characteristics. A p value $<0.05$ was considered to be statistically significant.

In this study, a stepwise backward elimination strategy was applied, along with multivariate logistic and Tobit regressions, to create reduced models. This strategy started a model with all candidate variables, then removed the variables which had the $\mathrm{p}$ values $>0.2$. Data were analysed using Stata software V.12.0 (StataCorp, College Station, Texas, USA).

\section{RESULTS}

Table 1 highlights the demographic characteristics of study respondents. Most of the participants were young adults or middle-aged, with about $43 \%$ of participants aged from 30 to 40 years and $37 \%$ of participants aged from 40 to 50 years. About half of participants (47\%) did not finish high school, and over $60 \%$ were current living with a spouse/partner. The majority of respondents were currently employed (93.6\%), but about half of them were self-employed $(47.5 \%)$.

Health-related characteristics and substance use behaviours among respondents are described in table 2 . We found that $25.5 \%$ of respondents were HIV-positive. Among them, the proportion of patients were currently on ART was $89.8 \%$. About $14 \%$ of patients reported mobility problems, and over $19.9 \%$ endorsed experiencing pain or discomfort. Thirty-one patients stated they were engaging in concurrent drug use during treatment with methadone $(13.4 \%)$. Approximately $76 \%$ of patients were current smokers, and $18.3 \%$ were hazardous drinkers. The proportion of patients having optimal adherence to MMT was $31.5 \%$.

Work productivity among respondents, as measured by the WPAI-GH, is presented in table 3. The rate of absenteeism (percentage of work time missed due to poor health) was $15.6 \%(\mathrm{SD}=31.7)$. The rate of presenteeism (percentage of reduction in work performance because of poor health) was lower than the rate of absenteeism, at $5.8 \%(\mathrm{SD}=19.0)$. The overall loss of productivity because of poor health among the entire sample was $11.2 \%$. We did not find a statistically significant difference in productivity lost between patients who had been enrolled in MMT for 1 year or less and those who had been enrolled in MMT for more than 1 year.

Table 4 describes characteristics related to work capability among the participants in our study. The most popular job endorsed by respondents was freelancer $(17.5 \%)$, followed by blue-collar worker $(10.6 \%)$, farmer (10.2\%) and small business owner $(9.4 \%)$. We found a low proportion of respondents actively seeking jobs in the past $(26.8 \%)$. Among the 71 patients currently under employment, there were $52.5 \%$ reported to be refused by an employer. Among the 22 patients who were refused jobs, the main reason for refusal was that they were drug users, which was endorsed by nine respondents $(28.13 \%)$. The preferred minimum wage at which to accept a job was 4.9 million Vietnam Dong (VND).

Table 5 shows the factors associated with working time missed due to health, overall work impairment due to health and ability to find jobs. Those who were HIV-positive and/or had other chronic diseases were found to be less actively searching for jobs than other participants $(\mathrm{OR}=0.21, \mathrm{p}<0.05)$. Various health-related characteristics 
Table 1 Demographic characteristics of respondents

\begin{tabular}{|c|c|c|c|c|c|c|c|}
\hline \multirow[b]{2}{*}{ Characteristic } & \multicolumn{2}{|c|}{$\begin{array}{c}\text { MMT } \\
\text { duration } \leq 12 \text { months } \\
(n=102)\end{array}$} & \multicolumn{2}{|c|}{$\begin{array}{c}\text { MMT } \\
\text { duration }>12 \text { months } \\
(n=139)\end{array}$} & \multicolumn{2}{|c|}{ Total $(n=241)$} & \multirow[b]{2}{*}{ p Value } \\
\hline & $\mathbf{N}$ & $\%$ & $\mathbf{N}$ & $\%$ & $\mathbf{N}$ & $\%$ & \\
\hline \multicolumn{8}{|l|}{ Age group (years) } \\
\hline$<30$ & 10 & 9.8 & 3 & 2.2 & 13 & 5.4 & 0.02 \\
\hline $30-40$ & 48 & 47.1 & 55 & 39.6 & 103 & 42.7 & \\
\hline $40-50$ & 31 & 30.4 & 59 & 42.5 & 90 & 37.3 & \\
\hline$\geq 50$ & 13 & 12.8 & 22 & 15.8 & 35 & 14.5 & \\
\hline \multicolumn{8}{|l|}{ Educational attainment } \\
\hline Less than high school & 50 & 49.0 & 61 & 45.5 & 111 & 47.0 & 0.13 \\
\hline High school & 48 & 47.1 & 58 & 43.3 & 106 & 44.9 & \\
\hline More than high school & 4 & 3.9 & 15 & 11.2 & 19 & 8.1 & \\
\hline \multicolumn{8}{|l|}{ Marital status } \\
\hline Single & 22 & 21.6 & 32 & 23.9 & 54 & 22.9 & 0.36 \\
\hline Live with spouse/partner & 61 & 59.8 & 86 & 64.2 & 147 & 62.3 & \\
\hline Widow/separate/divorced & 19 & 18.6 & 16 & 11.9 & 35 & 14.8 & \\
\hline \multicolumn{8}{|l|}{ Job } \\
\hline Unemployed & 9 & 8.8 & 6 & 4.5 & 15 & 6.4 & 0.39 \\
\hline Farmer/worker & 19 & 18.6 & 19 & 14.2 & 38 & 16.1 & \\
\hline Self-employed & 45 & 44.1 & 67 & 50.0 & 112 & 47.5 & \\
\hline Other & 29 & 28.4 & 42 & 31.3 & 71 & 30.1 & \\
\hline \multicolumn{8}{|l|}{ Location } \\
\hline Son Duong & 37 & 36.3 & 37 & 26.6 & 74 & 30.7 & 0.11 \\
\hline Tuyen Quang & 65 & 63.7 & 102 & 73.4 & 167 & 69.3 & \\
\hline
\end{tabular}

MMT, methadone maintenance treatment.

were found to be related to decreased work productivity, including 'experiencing problems with self-care', 'experiencing problems with mobility' and 'having pain/ discomfort'. Higher MMT adherence was associated with higher ability to work; however, a weak association was found between duration of treatment and a participant's workability.

\section{DISCUSSION}

While previous studies have documented MMT outcomes among drug users in Vietnam in terms of behaviour and health-related quality of life, ${ }^{21-24}$ our study is the first to measure the work capability and overall level of productivity among MMT patients. Our findings may provide evidence regarding the social aspect of MMT, as well as shed light on future directions to expand and improve the efficacy of MMT programmes in Vietnam.

We found a high rate of employment among MMT patients in Tuyen Quang Province. Over 90\% of participants in our sample reported currently holding a regular job. According to the 2015 Vietnamese National Report on Labor Survey, the employment-to-population ratio in the Northern Midlands and other northern mountainous areas of the country ranged from $83.4 \%$ to $86 \%$, and ratio nationwide was about $74.5 \%$ to $77.3 \% .^{32}$ The employment rate among non-MMT PWID was reported to be between $71.8 \%$ and $72.9 \%$, according to various studies. ${ }^{33-35}$ Compared with these numbers, the employment-to-population ratio among the 241 PWID in our study was slightly higher. One possible explanation for this higher ratio might be that most of the participants in our study were young adults or middle aged, which represent the two primary age ranges of the Vietnamese workforce. In addition, the Vietnamese Ministry of Health and international partners have gone to great lengths to expand substitution therapy for PWID (included MMT) and other social support interventions, which likely helped increase the employment rate in this population. ${ }^{22} 36-38$

Nonetheless, most of the participants' jobs were unstable (and nearly half of participants were self-employed). Other studies in Vietnam found similar results; indeed, on average, over $80 \%$ of patients on methadone in Vietnam did not feel able to participate in stable and long-time employment. ${ }^{21}{ }^{23}$ Daily medication schedule and time for travel to clinic might play a role as a potential barrier preventing patients from having stable jobs. 
Table 2 Health status and substance use behaviours among respondents

\section{MMT MMT}

duration $\leq 12$ months duration $>12$ months

\begin{tabular}{|c|c|c|c|c|c|c|c|}
\hline \multirow[b]{2}{*}{ Characteristics } & \multicolumn{2}{|c|}{$(n=102)$} & \multicolumn{2}{|c|}{$(n=139)$} & \multicolumn{2}{|c|}{ Total $(n=241)$} & \multirow[b]{2}{*}{ p Value } \\
\hline & $\mathbf{N}$ & $\%$ & $\mathbf{N}$ & $\%$ & $\mathbf{N}$ & $\%$ & \\
\hline Having acute diseases & 22 & 21.6 & 31 & 22.3 & 53 & 22.0 & 0.89 \\
\hline Having chronic diseases & 21 & 20.6 & 18 & 13.0 & 39 & 16.2 & 0.11 \\
\hline \multicolumn{8}{|l|}{ BMI categories } \\
\hline Underweight & 17 & 17.2 & 12 & 9.0 & 29 & 12.5 & 0.18 \\
\hline Normal & 77 & 77.9 & 114 & 85.7 & 191 & 82.3 & \\
\hline Overweight/obesity & 5 & 5.1 & 7 & 5.3 & 12 & 5.2 & \\
\hline \multicolumn{8}{|l|}{ HRQOL } \\
\hline Having problems in mobility & 14 & 13.7 & 19 & 14.2 & 33 & 14.0 & 0.92 \\
\hline Having problems in self-care & 12 & 11.8 & 13 & 9.7 & 25 & 10.6 & 0.61 \\
\hline Having problems in usual activities & 15 & 14.7 & 19 & 14.2 & 34 & 14.4 & 0.91 \\
\hline Pain/discomfort & 16 & 15.7 & 31 & 23.1 & 47 & 19.9 & 0.16 \\
\hline Anxiety/depression & 26 & 25.5 & 35 & 26.1 & 61 & 25.9 & 0.91 \\
\hline HIV-positive & 24 & 24.2 & 35 & 26.5 & 59 & 25.5 & 0.25 \\
\hline HIV-positive patients currently on ART & 23 & 95.8 & 30 & 85.7 & 53 & 89.8 & $<0.01$ \\
\hline Current smoker & 72 & 72.7 & 102 & 77.9 & 174 & 75.7 & 0.49 \\
\hline Current hazardous drinker & 12 & 11.8 & 32 & 23.0 & 44 & 18.3 & 0.03 \\
\hline Current drug use & 20 & 20.0 & 11 & 8.3 & 31 & 13.4 & 0.01 \\
\hline \multicolumn{8}{|l|}{ Number of drug rehabilitation } \\
\hline 0 times & 18 & 17.7 & 17 & 12.2 & 35 & 14.5 & 0.60 \\
\hline One time & 29 & 28.4 & 43 & 30.9 & 72 & 29.9 & \\
\hline Two times & 19 & 18.6 & 32 & 23.0 & 51 & 21.2 & \\
\hline$>$ Two times & 36 & 35.3 & 47 & 33.8 & 83 & 34.4 & \\
\hline \multirow[t]{2}{*}{ Adhered to MMT } & 31 & 30.4 & 45 & 32.4 & 76 & 31.5 & 0.74 \\
\hline & Mean & SD & Mean & SD & Mean & SD & $p$ Value \\
\hline EQ-5D-5L index score & 0.89 & 0.20 & 0.88 & 0.21 & 0.88 & 0.20 & 0.80 \\
\hline VAS score & 81.9 & 16.3 & 81.8 & 14.5 & 81.8 & 15.3 & 0.99 \\
\hline
\end{tabular}

ART, antiretroviral therapy; BMI, body mass index; EQ-5D-5L, EuroQol-five dimensions-five levels; HRQOL, health-related quality of life; MMT, methadone maintenance treatment; VAS, visual analogue scale.

Table 3 Work productivity among respondents

\section{MMT MMT}

duration $\leq 12$ months duration $>12$ months

\begin{tabular}{|c|c|c|c|c|c|c|c|}
\hline \multirow[b]{2}{*}{ Characteristics } & \multicolumn{2}{|c|}{$(n=102)$} & \multicolumn{2}{|c|}{$(n=139)$} & \multicolumn{2}{|c|}{ Total $(n=241)$} & \multirow[b]{2}{*}{ p Value } \\
\hline & Mean & SD & Mean & SD & Mean & SD & \\
\hline $\begin{array}{l}\text { Per cent work time missed because of } \\
\text { poor health }\end{array}$ & 13.9 & 31.0 & 16.7 & 32.4 & 15.6 & 31.7 & 0.69 \\
\hline $\begin{array}{l}\text { Per cent impairment while working } \\
\text { because of poor health }\end{array}$ & 8.1 & 23.6 & 4.3 & 15.5 & 5.8 & 19.0 & 0.44 \\
\hline $\begin{array}{l}\text { Per cent overall work impairment } \\
\text { because of poor health }\end{array}$ & 8.0 & 24.3 & 13.3 & 30.7 & 11.2 & 28.3 & 0.65 \\
\hline $\begin{array}{l}\text { Per cent activity impairment because of } \\
\text { poor health }\end{array}$ & 6.9 & 21.8 & 3.9 & 16.5 & 5.1 & 18.8 & 0.17 \\
\hline
\end{tabular}

MMT, methadone maintenance treatment. 
Table 4 Work capability among respondents

\begin{tabular}{|c|c|c|c|c|c|c|c|}
\hline \multirow[b]{2}{*}{ Characteristics } & \multicolumn{2}{|c|}{$\begin{array}{c}\text { MMT } \\
\text { duration } \leq 12 \text { months } \\
(n=102)\end{array}$} & \multicolumn{2}{|c|}{$\begin{array}{c}\text { MMT } \\
\text { duration }>12 \text { months } \\
(n=139)\end{array}$} & \multicolumn{2}{|c|}{ Total $(n=241)$} & \multirow[b]{2}{*}{ p Value } \\
\hline & $\mathbf{N}$ & $\%$ & $\mathbf{N}$ & $\%$ & $\mathbf{N}$ & $\%$ & \\
\hline \multicolumn{8}{|l|}{ Currently working at a sustainable job } \\
\hline Blue-collar & 9 & 8.9 & 16 & 11.9 & 25 & 10.6 & 0.85 \\
\hline Farmer & 10 & 9.9 & 14 & 10.5 & 24 & 10.2 & \\
\hline Small business at home & 11 & 10.9 & 11 & 8.2 & 22 & 9.4 & \\
\hline Freelancer & 16 & 15.8 & 25 & 18.7 & 41 & 17.5 & \\
\hline Others & 55 & 54.5 & 68 & 50.8 & 123 & 52.3 & \\
\hline \multicolumn{8}{|l|}{ Have actively sought jobs in the past } \\
\hline No & 76 & 74.5 & 96 & 72.2 & 172 & 73.2 & 0.69 \\
\hline Yes & 26 & 25.5 & 37 & 27.8 & 63 & 26.8 & \\
\hline \multicolumn{8}{|l|}{ Being accepted by an employer } \\
\hline Yes & 9 & 36.0 & 20 & 55.6 & 29 & 47.5 & 0.13 \\
\hline \multirow[t]{2}{*}{ No } & 16 & 64.0 & 16 & 44.4 & 32 & 52.5 & \\
\hline & Mean & SD & Mean & SD & Mean & SD & p Value \\
\hline \multirow[t]{2}{*}{ Minimum salary to accept job (Mil VND) } & 5.5 & 10.19 & 4.4 & 2.36 & 4.9 & 6.89 & 1.00 \\
\hline & $\mathbf{n}$ & $\%$ & & & & & \\
\hline \multicolumn{8}{|l|}{$\begin{array}{l}\text { Reason for not being accepted by } \\
\text { employer (if applicable) }\end{array}$} \\
\hline Drug user & 9 & 28.13 & & & & & \\
\hline HIV patients & 2 & 6.25 & & & & & \\
\hline Insufficient capacity & 1 & 3.13 & & & & & \\
\hline Unknown & 10 & 31.25 & & & & & \\
\hline
\end{tabular}

MMT, methadone maintenance treatment.

In addition, the low level of educational attainment and lack of vocational skills among PWID in Tuyen Quang might be great obstacles to having stable jobs. Our results showed that a very low proportion of participants had a higher degree, and about half of them did not finish high school. They were mainly employed in low-skill jobs such as being a freelancer or working as a blue-collar worker. The Government of Vietnam, collaborated with international groups, has established several policies and interventions to support the creation of employment opportunities for PWID after treatment, including vocational training, financial assistance and peer support groups. ${ }^{37-39}$ However, these endeavours have some notable limitations. First, there is a lack of diversity within the workforce in Vietnam. Many patients may not be able to apply what they have learnt after returning to the community because of the demands of the labour market. In addition, despite being successful in treatment, PWID may still suffer from many health problems including HIV and psychological ailments. In our study, the HIV-positive rate was $25.5 \%$ among participants, and those who had HIV and other chronic diseases were less likely to actively seek jobs. In addition, for a long time, people who inject drugs in Vietnam have been judged as engaging in 'social evils' and faced a variety of barriers due to stigma and discrimination. Such barriers may pose the biggest threat to their ability to find stable employment. A study by Tran et al found that enrolment in MMT may reduce internalised stigma and discrimination among PWID. ${ }^{40}$ However, in our settings, the rate of experiencing blame, shame and isolation from the community and the workplace were relative high. ${ }^{41}$ Moreover, more than half of the individuals who participated in our study (particularly those who were HIV-positive) reported that they had been turned away by employers in the past.

Using the WPAI-GH instrument, we found a very low level of impairment in work productivity and daily activities among respondents. Similar results have been noted in other countries. A 1-year study conducted among PWID enrolled in MMT in Taiwan found that individuals enrolled in MMT saw decreased expenditures for illegal drugs and health services, in conjunction with a rise in employment. ${ }^{42}$ Employment and income rates increased by half among patients in the USA after 6 months of being on MMT in a study conducted by Corsi et al. ${ }^{17}$ In our study, we identified various factors that were associated with lost productivity among respondents. First respondents who endorsed problems in mobility, self-care and pain were 


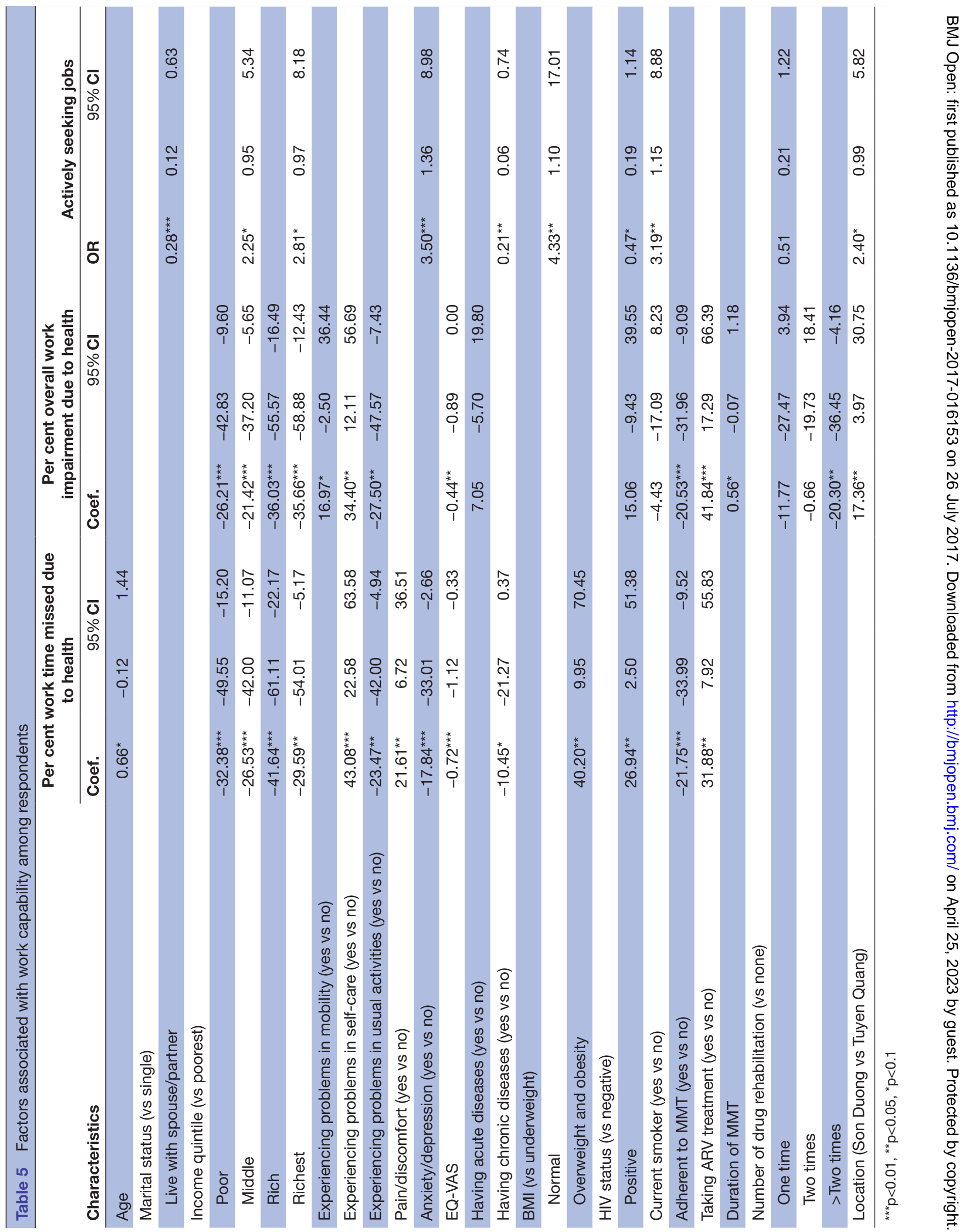


more likely to report a higher loss of productivity. Additionally, patients who were HIV-positive and currently taking ARV had higher rates of absenteeism than other participants. Many studies have demonstrated the drug interactions between $\mathrm{ARV}$ and methadone, which require patients to take higher doses of methadone in order to see an effect. ${ }^{43}$ After taking such a high dose, patients may suffer from side effects, including sleep problems, nausea and vomiting, ${ }^{45}$ which may reduce their performance and ability to work. However, these side effects are often not long lasting and employers could make allowance for them. In addition, for HIV-positive PWID, a collaboration among health workers at MMT and ARV clinics is necessary. Other health conditions including health nutrition status and the co-existence of other chronic diseases were also shown to be associated with patients' ability to join the workforce. Overall, our findings confirmed the results of other studies recommending that HIV prevention and treatment services, pain management as well as general healthcare services, should be integrated to maximise the effectiveness of each of the programmes. ${ }^{22} 234647$ Other MMT-related factors such as the duration of MMT, depression and concurrent substance abuse were found to have no or weak correlation with rates of absenteeism and overall work impairment.

Our study points to several ways to improve the efficiency of MMT and HIV/AIDS services in Vietnam. First, a high proportion of the participants in our study were employed; however, the high proportion of participants held unstable occupations and did not require many skills. This suggests that current vocational training and career support may not be sufficient to meet the career demands of this population. Future job-related policy for MMT patients should be based on the preferences and the demands of the patients and the labour market. In addition, many patients reported that they were not accepted by an employer because of their drug use history and HIV status. This finding reflects the considerable stigma and discrimination towards PWID and people living with HIV/ADS in Vietnam that still exists. Follow-up interventions should be conducted in a synchronous manner to more efficiently remove the barrier of stigma and discrimination. We also found several health-related characteristics, including being HIV-positive, cotreatment with MMT and ARV and endorsing significant pain, were associated with lower work productivity among participants. Therefore, the collaboration between MMT and other healthcare services is necessary in order to see improved work productivity outcomes. Counselling during treatment to improve and maintain patients' adherence to treatment is also important.

This study has several limitations. First, we employed a cross-sectional study design without a control group. Thus, we cannot compare changes in outcomes for the people in our study as compared with others without similar exposure. To best account for this limitation, we divided our sample into two groups: one that included individuals who had been in MMT for 1 year or less, and another group that had been in MMT for more than
1 year. Yet our small sample size may have reduced the statistical power. Another limitation is that our data are based on patients' self-reports, which may lead to recall bias. Finally, the data are not allowed to compare the work experiences of patients before and after participating treatment, which should be examined in future studies in order to provide comprehensive evidence to improve the effectiveness of MMT programme in Vietnam.

\section{CONCLUSION}

In conclusion, our study highlights the high employment rate and work productivity among PWID enrolled in MMT in a remote area of Vietnam. Various factors associated with workability have been determined through our work, which could be useful in helping to improve the quality and expansion of MMT programmes across the country.

\section{Author affiliations}

${ }^{1}$ Institute for Global Health Innovations, Duy Tan University, Da Nang, Vietnam ${ }^{2}$ University of California Berkeley School of Public Health, Berkeley, California, USA ${ }^{3}$ School of Medicine and Pharmacy, Vietnam National University, Hanoi, Vietnam

${ }^{4} J o h n s$ Hopkins Bloomberg School of Public Health, Baltimore, Maryland, USA

${ }^{5}$ Institute for Preventive Medicine and Public Health, Hanoi Medical University, Hanoi, Vietnam

${ }^{6}$ Authority of HIV/AIDS Control, Ministry of Health, Hanoi, Vietnam

${ }^{7}$ Department of Immunology and Allergy, National Otolaryngology Hospital, Hanoi, Vietnam

Acknowledgements The authors would like to thank the patients and their families for their participation in this study. They would also like to thank The Vietnam Authority of HIV/AIDS Control, The Hanoi School of Public Health and the Tuyen Quang Provincial Aids Center for their help and support.

Contributors HLTN, VMN, VLB, CTN, LHN, BXT, HVN, CHD, CAL, VTMT conceived of the study, and participated in its design and implementation and wrote the manuscript. HLTN, VMN and CTN analysed the data. All authors read and approved the final manuscript.

\section{Competing interests None declared.}

Patient consent Parental/guardian consent obtained.

Ethics approval IRB of Vietnam Authority of HIV/AIDS Control.

Provenance and peer review Not commissioned; externally peer reviewed.

Data sharing statement The data that support the findings of this study were made available by the Vietnam Authority of HIV/AIDS Control, but there were a few restrictions on the availability of these data. The data were used under licence for the current study, and so are not publicly available. Data are however available from the authors on reasonable request and with permission from the Vietnam Authority of HIV/AIDS Control.

Open Access This is an Open Access article distributed in accordance with the Creative Commons Attribution Non Commercial (CC BY-NC 4.0) license, which permits others to distribute, remix, adapt, build upon this work non-commercially, and license their derivative works on different terms, provided the original work is properly cited and the use is non-commercial. See: http://creativecommons.org/ licenses/by-nc/4.0/

(C) Article author(s) (or their employer(s) unless otherwise stated in the text of the article) 2017. All rights reserved. No commercial use is permitted unless otherwise expressly granted.

\section{REFERENCES}

1. Degenhardt L, Whiteford HA, Ferrari AJ, et al. Global burden of disease attributable to illicit drug use and dependence: findings from the Global Burden of Disease Study 2010. Lancet 2013;382:1564-74. 
2. Mathers BM, Degenhardt L, Phillips B, et al. Global epidemiology of injecting drug use and HIV among people who inject drugs: a systematic review. Lancet 2008;372:1733-45.

3. Nelson PK, Mathers BM, Cowie B, et al. Global epidemiology of hepatitis $B$ and hepatitis $C$ in people who inject drugs: results of systematic reviews. Lancet 2011;378:571-83.

4. Mathers BM, Degenhardt L, Bucello C, et al. Mortality among people who inject drugs: a systematic review and meta-analysis. Bull World Health Organ 2013;91:102-23.

5. NDIC. National Drug Threat Assessment. ;2011 https://www.justice. gov/archive/ndic/pubs44/44849/44849p.pdf.

6. Lin SH, Chen KC, Lee SY, et al. The economic cost of heroin dependency and quality of life among heroin users in Taiwan. Psychiatry Res 2013;209:512-7.

7. Richardson L, Wood E, Li K, et al. Factors associated with employment among a cohort of injection drug users. Drug Alcohol Rev 2010;29:293-300.

8. French MT, Roebuck MC, Alexandre PK. Illicit Drug Use, Employment, and Labor Force participation. South Econ J 2001;68:349-68.

9. Mattick RP, Breen C, Kimber J, et al. Methadone maintenance therapy versus no opioid replacement therapy for opioid dependence. Cochrane Database Syst Rev 2009;3:Cd002209.

10. Mattick RP, Breen C, Kimber J, et al. Buprenorphine maintenance versus placebo or methadone maintenance for opioid dependence. Cochrane Database Syst Rev 2014:Cd002207.

11. Sun HM, Li XY, Chow EP, et al. Methadone maintenance treatment programme reduces criminal activity and improves social well-being of drug users in China: a systematic review and meta-analysis. BMJ Open 2015;5:e005997.

12. Gowing L, Farrell M, Bornemann R, et al. Substitution treatment of injecting opioid users for prevention of HIV infection. Cochrane Database Syst Rev 2008;2:Cd004145.

13. Karki P, Shrestha R, Huedo-Medina TB, et al. The impact of Methadone Maintenance treatment on HIV risk behaviors among High-Risk injection drug users: a systematic review. Evid Based Med Public Health 2016;2:e1229.

14. Xiao L, Wu Z, Luo W, et al. Quality of life of outpatients in methadone maintenance treatment clinics. J Acquir Immune Defic Syndr 2010;53(Suppl 1):S116-S120.

15. Wang PW, Wu HC, Yen $\mathrm{CN}$, et al. Change in quality of life and its predictors in heroin users receiving methadone maintenance treatment in Taiwan: an 18-month follow-up study. Am J Drug Alcohol Abuse 2012;38:213-9.

16. Baharom N, Hassan MR, Ali N, et al. Improvement of quality of life following 6 months of methadone maintenance therapy in Malaysia. Subst Abuse Treat Prev Policy 2012;7:32.

17. Corsi KF, Lehman WK, Booth RE. The effect of methadone maintenance on positive outcomes for opiate injection drug users. $J$ Subst Abuse Treat 2009;37:120-6.

18. Hsiao CY, Chen KC, Lee LT, et al. The reductions in monetary cost and gains in productivity with methadone maintenance treatment: one year follow-up. Psychiatry Res 2015;225:673-9.

19. $\mathrm{MOH}$. HIV/STI Integrated Biological and Behavioral Surveillance (IBBS) in Vietnam: round III. Hanoi 2014.

20. MOH. Vietnam National Response to HIV/AIDS Report. Hanoi 2016.

21. Tran BX, Nguyen LT. Impact of methadone maintenance on health utility, health care utilization and expenditure in drug users with HIV/ AIDS. Int J Drug Policy 2013;24:e105-e110.

22. Tran BX, Ohinmaa A, Duong AT, et al. Cost-effectiveness of methadone maintenance treatment for HIV-positive drug users in Vietnam. AIDS Care 2012;24:283-90.

23. Tran BX, Nguyen LH, Nong VM, et al. Behavioral and quality-of-life outcomes in different service models for methadone maintenance treatment in Vietnam. Harm Reduct J 2016;13:4.

24. Hoang TV, Ha TT, Hoang TM, et al. Impact of a methadone maintenance therapy pilot in Vietnam and its role in a scaled-up response. Harm Reduct J 2015;12:39.

25. Tran BX, Phan HT, Nguyen LH, et al. Economic vulnerability of methadone maintenance patients: implications for policies on copayment services. Int J Drug Policy 2016;31:131-7.
26. Reilly MC, Zbrozek AS, Dukes EM. The validity and reproducibility of a work productivity and activity impairment instrument. Pharmacoeconomics 1993;4:353-65.

27. daCosta DiBonaventura M, Gupta S, Cho M, et al. The association of HIV/AIDS treatment side effects with health status, work productivity, and resource use. AIDS Care 2012;24:744-55.

28. Group E. EQ-5D-5L user Guide: basic information on how to use the EQ-5D-5L instrument. secondary EQ-5D-5L user Guide: basic information on how to use the EQ-5D-5L instrument. $2011 \mathrm{http}: / /$ www.euroqol.org/fileadmin/user_upload/Documenten/PDF/Folders Flyers/UserGuide_EQ-5D-5L.pdf.

29. Bradley KA, DeBenedetti AF, Volk RJ, et al. AUDIT-C as a brief screen for alcohol misuse in primary care. Alcohol Clin Exp Res 2007;31:1208-17.

30. Giordano TP, Guzman D, Clark R, et al. Measuring adherence to antiretroviral therapy in a diverse population using a visual analogue scale. HIV Clin Trials 2004;5:74-9.

31. Kalichman SC, Amaral CM, Swetzes C, et al. A simple single-item rating scale to measure medication adherence: further evidence for convergent validity. J Int Assoc Physicians AIDS Care 2009;8:367-74.

32. VGSO. Report on Labor Force survey 2015. Hanoi: Ministry of Investment and Planing 2016.

33. Quan VM, Go VF, Nam leV, et al. Risks for HIV, HBV, and HCV infections among male injection drug users in northern Vietnam: a case-control study. AIDS Care 2009;21:7-16.

34. Go VF, Frangakis C, Le Minh N, et al. Effects of an HIV peer prevention intervention on sexual and injecting risk behaviors among injecting drug users and their risk partners in Thai Nguyen, Vietnam: a randomized controlled trial. Soc Sci Med 2013;96:154-64.

35. Go VF, Minh NL, Frangakis C, et al. Decreased injecting is associated with increased alcohol consumption among injecting drug users in northern Vietnam. Int J Drug Policy 2013;24:304-11.

36. Le LT, Grau LE, Nguyen HH, et al. Coalition building by drug user and sex worker community-based organizations in Vietnam can lead to improved interactions with government agencies: a qualitative study. Harm Reduct J 2015;12:38.

37. Hayes-Larson E, Grau LE, Khoshnood K, et al. Drug users in Hanoi, Vietnam: factors associated with membership in community-based drug user groups. Harm Reduct J 2013;10:33-

38. Li L, Hien NT, Lin C, et al. An intervention to improve mental health and family well-being of injecting drug users and family members in Vietnam. Psychol Addict Behav 2014;28:607-13.

39. Ahmed T, Long NT, Huong PTT, et al. HIV and Injecting Drug Users in Vietnam: an overview of policies and responses. World Med Health Policy 2014;6:395-418.

40. Tran BX, Vu PB, Nguyen LH, et al. Drug addiction stigma in relation to methadone maintenance treatment by different service delivery models in Vietnam. BMC Public Health 2016;16:238.

41. Van Nguyen H, Nguyen HL, Mai HT, et al. Stigmatization among methadone maintenance treatment patients in mountainous Areas in northern Vietnam. Harm Reduct J 2017;14:11.

42. Hsiao CY, Chen KC, Lee LT, et al. The reductions in monetary cost and gains in productivity with methadone maintenance treatment: one year follow-up. Psychiatry Res 2015;225:673-9.

43. Gourevitch MN, Friedland GH. Interactions between methadone and medications used to treat HIV infection: a review. Mt Sinai J Med 2000;67:429-36.

44. Gerber JG, Rosenkranz S, Segal Y, et al. Effect of ritonavir/saquinavir on stereoselective pharmacokinetics of methadone: results of AIDS clinical Trials Group (ACTG) 401. J Acquir Immune Defic Syndr2001;27:153-60.

45. Zhao L, Holzemer WL, Johnson M, et al. HIV infection as a predictor of methadone maintenance outcomes in chinese injection drug users. AIDS Care 2012;24:195-203.

46. Tran BX, Nguyen LH, Phan HT, et al. Patient satisfaction with Methadone Maintenance treatment in Vietnam: A comparison of Different Integrative-Service delivery models. PLoS One 2015;10:e0142644

47. Kato M, Granich R, Bui DD, et al. The potential impact of expanding antiretroviral therapy and combination prevention in Vietnam: towards elimination of HIV transmission. J Acquir Immune Defic Syndr 2013;63:e142-e49. 